\title{
AS AÇÕES DAS INSTITUIÇÕES RELIGIOSAS DENTRO DO SISTEMA PRISIONAL DAS REGIÕES SUL/SUDESTE BRASILEIRO NOS ÚLTIMOS DOIS ANOS NA PERSPECTIVA DE RESSOCIALIZAÇÃO: UMA REVISÃO BIBLIOGRÁFICA
}

\author{
The actions of religious institutions within the prison system of the South / Sudeste \\ Brazilian regions in the last two years from the perspective of resocialization: a \\ bibliographic review
}

\section{Ediene Valéria Dourado Guimarães Pereira - UNEB - Bahia/Brasil} Sandra Célia Coelho Gomes da Silva - UNEB - Bahia/Brasil

\begin{abstract}
RESUMO: No contexto atual, percebe-se que diferentes instituições começaram a discutir melhorias no sistema prisional brasileiro. As problemáticas que afligem estes espaços deixaram de ser debatidas somente por estudiosos da área jurídica, adentrando a outras áreas do conhecimento, a exemplo das ciências humanas e das religiões. Desta forma, o presente estudo tem por objetivo analisar/pontuar quais as propostas de ressocialização que as instituições religiosas do Sul/Sudeste fazem dentro do sistema prisional brasileiro nos últimos dois anos. Com a seguinte questão norteadora: Quais as ações das instituições religiosas dentro do sistema prisional do Sul/Sudeste brasileiro na perspectiva de ressocialização nos últimos dois anos? Tendo como abordagem metodológica uma revisão bibliográfica/descritiva de literatura no banco de teses e dissertações da CAPES, fazendo um mapeamento das regiões sul/sudeste e dos trabalhos que correspondem à temática com descritores religião, sistema prisional e ressocialização das Instituições de Ensino Superior (públicas e privadas). Diante das análises, foram registrados momentos de cerimônias religiosas e espaços confessionais, uma disputa de poder entre as igrejas e conversões de almas. Práticas que ferem a lei de liberdade religiosa. Assim, em apenas um trabalho identificou-se uma Capela Ecumênica, apresentada como um espaço de oportunidades das diversas religiões.
\end{abstract}

Palavras-chave: Religião. Sistema prisional. Ressocialização. Instituição.

ABSTRACT: In the current context, it is clear that different institutions have started to discuss improvements in the Brazilian prison system. The problems that afflict these spaces are no longer debated only by scholars in the legal field, but have entered other areas of knowledge, such as the humanities and religions. Thus, the present study aims to analyze / point out what re-socialization proposals that religious institutions in the South / Southeast have made within the Brazilian prison system in the last two years. With the following guiding question: What are the actions of religious institutions within the prison system of the South / Southeast of Brazil in the perspective of resocialization in the last two years? Having as methodological approach a bibliographic / descriptive review of literature in the CAPES thesis and dissertation database, mapping the south / southeast regions and the works that correspond to the theme with descriptors religion, prison system and resocialization of Higher Education Institutions (public and private). In view of the analyzes, moments of religious ceremonies and confessional spaces, a power struggle between churches and conversions of souls were recorded. Practices that violate 
the religious freedom law. Thus, in just one work, an Ecumenical Chapel was identified, presented as a space for opportunities for different religions.

Keyword: Religion, Prison system, Resocialization, Institution.

\section{INTRODUÇÃ̃O}

O crescimento desenfreado da população brasileira e a falta de políticas públicas para as classes menos favorecidas colaboram de forma significativa para o aumento da violência no Brasil. Conhecer o sistema prisional brasileiro e sua atual conjuntura faz-se necessário nos dias atuais. Para se conseguir a transformação dos apenados que se encontram sobre medida de privação da liberdade, o Estado necessita buscar mecanismos que visem sua transformação, e quando este não assume suas responsabilidades previstas em leis, aparecem, assim, diversas entidades não governamentais que almejam colaborar para a diminuição dos problemas que atingem nosso país. Assim, a religião surge como uma doutrina que vem ganhando espaço no sistema prisional, com o intuito de ressocializar.

Para muitas pessoas, as práticas religiosas colaboram de forma significativa na conduta social do apenado. Desta forma, o presente artigo tem como objetivo geral: analisar/pontuar quais as propostas de ressocialização que as instituições religiosas fazem dentro do sistema prisional das regiões sul/sudeste brasileiro nos últimos dois anos. De tal modo, faz-se necessário discorrer sobre os seguintes objetivos específicos: identificar as principais produções de conhecimento que discutem sobre a temática ressocialização, sistema prisional e religião dentro dos presídios das regiões sul/sudeste nos anos de 2017 e 2018; verificar a aplicação de medidas que contribuam para a ressocialização dos presos, com vistas a desenvolver o conhecimento de atividades educacionais não formais, desenvolvidas por instituições religiosas da região sul/sudeste nos últimos dois anos, durante a permanência dos apenados, quando estes encontravam-se reclusos.

O espaço de interesse pelo tema "ressocialização" surgiu de uma experiência acadêmica, quando trabalhei por alguns anos em um projeto intitulado de Programa de Erradicação do Trabalho Infantil (PETI), atualmente conhecido pelo nome de Serviço de Convivência e Fortalecimento de Vínculos (SCFV). O projeto mencionado acolhia crianças/adolescentes em horários opostos ao da escola regular. Seu funcionamento

Educação, Psicologia e Interfaces, Volume 4, Número 3, p. 1-14, Julho/Setembro, 2020.

ISSN: 2594-5343. DOI: 10.37444/issn-2594-5343.v4i3.295 
As ações das instituições religiosas dentro do sistema prisional das regiões Sul/Sudestedo brasileiro nos últimos dois anos na perspectiva de ressocialização: uma revisão bibliográfica.

acontecia em bairros periféricos da cidade de Guanambi/BA e foi neste contexto que pude conviver com adolescentes, e seus genitores, que se encontravam ou já teriam passado pelo sistema prisional Municipal ou Estadual Baiano.

A relevância social da pesquisa mediatizou a necessidade de refletir sobre o cumprimento da Lei n ${ }^{\circ}$ 7.210, de 11 de Julho de 1984, a lei de Execução Penal, garantindo os direitos individuais dos presos e dando voz aos sujeitos da pesquisa no que tange à sua prática religiosa.

O trabalho aqui proposto pretende apresentar uma breve análise das ações educacionais não formais realizadas por Instituições religiosas dentro dos presídios do sul/sudeste brasileiro nos anos de 2017 e 2018, de forma a contribuir com a emancipação dos presos enquanto estes encontrarem-se privados de liberdade. Por tanto almeja-se identificar as principais produções de conhecimento que discutem sobre "Ressocialização" no contexto religioso nos últimos dois anos na região sul/sudeste do Brasil.

A análise foi realizada através da revisão bibliográfico-descritiva. Utilizou-se o banco de teses e dissertações da CAPES, fazendo um mapeamento dos trabalhos que correspondem à temática, com os descritores religião, sistema prisional, ressocialização na região sul/sudeste nos últimos dois anos.

\section{METODOLOGIA}

Este estudo será pautado em uma pesquisa bibliográfica através da revisão integrativa, mediante análise da literatura utilizada, extraindo e aplicando os pontos relevantes ao tema, a fim de justificar as ações apresentadas neste trabalho. Conforme Mendes, Silveira e Galvão (2008), a pesquisa integrativa segue seis etapas distintas, são elas: identificação do tema e seleção da hipótese; estabelecimento de critérios para inclusão e exclusão de estudos/ amostragens ou busca na literatura; definição das informações a serem extraídas dos estudos selecionados/ categorização dos estudos; avaliação dos estudos incluídos na revisão integrativa; interpretação dos resultados; apresentação da revisão/síntese do conhecimento.

Foi utilizado o banco de teses e dissertações da CAPES, com os descritores: religião, sistema prisional e ressocialização. Após a busca, foram encontrados 23.2517 trabalhos nos anos de 2017/2018, sendo 18896 (mestrado) e 9076 (doutorado). Ao refinar

Educação, Psicologia e Interfaces, Volume 4, Número 3, p. 1-14, Julho/Setembro, 2020.

ISSN: 2594-5343. DOI: 10.37444/issn-2594-5343.v4i3.295 
para a área de ciências humanas foram localizados 3545 trabalhos, 2362 (mestrado) e 1183 (doutorado). Por último, foram encontrados 914 trabalhos que correspondem aos descritores. Após criar uma pasta para separação das pesquisas encontradas, notou-se que existiam 02 trabalhos correspondentes da região sul (dissertação) e 02 (teses) da região sudeste.

Para melhor compreensão dos trabalhos acadêmicos foram realizadas leituras dos títulos, metodologias, resumos, introduções e conclusões. Para sistematização dos dados, foi produzido um quadro contendo todos os trabalhos selecionados para análise. O quadro dispõe de classificação das universidades, dos autores, do tipo de trabalho (dissertações e teses), títulos, palavras-chaves e regiões.

O levantamento de dados ocorreu no período de setembro/2019 a novembro/2019, pesquisando sobre os descritores: religião, sistema prisional e ressocialização, sendo encontrados textos vinculados às universidades federais e privadas, dentro dos sistemas de pós-graduação das universidades das regiões Sul/Sudeste. Um dos critérios de análises foi a disponibilidade dos textos na íntegra, disponíveis nos repositórios ou bases de dados, bem como, excluídas as publicações incompletas, que ultrapassassem o período estabelecido ou fugisse da temática abordada. Segue abaixo a apresentação do quadro e a análise dos dados coletados.

\section{RESULTADOS E DISCUSSÕES}

Após estudos, foram encontrados um total de quatro trabalhos, duas dissertações de mestrado e duas testes de doutorado. Nas análises e seleção de critério anteriormente mencionados, foi identificado que as produções acadêmicas pertencem aos programas de pós-graduação em Ciência das Religiões, Teologia, Geografia e Psicologia da Universidade Federal do Paraná (PR); Curso de Mestrado Profissional Teologia e Sociedade da Faculdade EST (PR); Programa de Pós-Graduação em Psicologia da Universidade Federal de São João Del Rei (MG) e Programa de Mestrado Profissional em Ciências das Religiões da Faculdade Unida de Vitória (ES). Sendo um total de duas instituições públicas federais e duas instituições privadas. Para Vianna (2003, p. 15) "a observação, como técnica científica, pressupõe a realização de uma pesquisa com objetivos criteriosamente formulados, planejamento adequado, registro sistemático dos 
As ações das instituições religiosas dentro do sistema prisional das regiões Sul/Sudestedo brasileiro nos últimos dois anos na perspectiva de ressocialização: uma revisão bibliográfica.

dados, verificação da validade de todo o desenrolar do seu processo e da confiabilidade dos resultados".

Sendo assim, tivemos como critério a seleção sistemática dos trabalhos, estabelecendo 05 fundamentos para estudo e, posteriormente, análises dos resultados. Os critérios foram: identificar, apresentar, explicar, relacionar e, por último, concluir.

Para melhor compreensão dos dados coletados, foi construído um quadro contendo todos

Trabalhos encontrados pertencentes às regiões Sul e Sudeste.

Quadro 01: Publicações Referentes à Temática: Sistema Prisional, Ressocialização e Religião (ano de 2017/2018)

\begin{tabular}{|c|c|c|c|c|c|c|}
\hline Universidade & Autor & Ano & $\begin{array}{l}\text { Tipo de } \\
\text { trabalho }\end{array}$ & Título & Palavras-chave & Região \\
\hline $\begin{array}{l}\text { Universidade } \\
\text { Federal do } \\
\text { Paraná }\end{array}$ & $\begin{array}{l}\text { Danilo } \\
\text { Henrique } \\
\text { Martins }\end{array}$ & 2017 & TESE & $\begin{array}{l}\text { Unidade prisional como } \\
\text { espaço total: a religião na } \\
\text { colônia penal } \\
\text { agroindustrial do Paraná }\end{array}$ & $\begin{array}{l}\text { Unidade Prisional. } \\
\text { Espaço Total. } \\
\text { Metáfora Teatral. } \\
\text { Instituição Total. } \\
\text { Erving Goffman. }\end{array}$ & Sul \\
\hline $\begin{array}{c}\text { Faculdades } \\
\text { EST }\end{array}$ & $\begin{array}{l}\text { Iarani } \\
\text { Augusta } \\
\text { Lauxen }\end{array}$ & 2018 & TESE & $\begin{array}{l}\text { Por detrás do muro } \\
\text { cinza: contribuições da } \\
\text { assistência religiosa no } \\
\text { tratamento penal }\end{array}$ & $\begin{array}{c}\text { Assistência } \\
\text { Religiosa; Pessoas } \\
\text { privadas de liberdade; }\end{array}$ & Sul \\
\hline $\begin{array}{l}\text { Universidade } \\
\text { Federal de São } \\
\text { João Del-Rei }\end{array}$ & $\begin{array}{c}\text { Luiz } \\
\text { Felipe } \\
\text { Viana } \\
\text { Cardoso }\end{array}$ & 2018 & $\begin{array}{l}\text { DISSER } \\
\text { TAÇÃO }\end{array}$ & $\begin{array}{l}\text { Da reintegração social a } \\
\text { inclusão psicossocial: um } \\
\text { estudo com pessoas que } \\
\text { cumpriram pena de } \\
\text { privação de liberdade no } \\
\text { método APAC. }\end{array}$ & $\begin{array}{l}\text { Reintegração Social; } \\
\text { Inclusão Psicossocial; } \\
\text { APAC; Sistema } \\
\text { Prisional; Egressos. }\end{array}$ & Sudeste \\
\hline $\begin{array}{l}\text { Faculdade } \\
\text { Unida de } \\
\text { Vitória }\end{array}$ & $\begin{array}{l}\text { Bruno } \\
\text { Moraes } \\
\text { Costa }\end{array}$ & 2018 & $\begin{array}{l}\text { DISSER } \\
\text { TAÇÃO }\end{array}$ & $\begin{array}{l}\text { Ressocialização mediada } \\
\text { pela assistência religiosa: } \\
\text { direito dos encarcerados } \\
\text { no sistema penitenciário }\end{array}$ & $\begin{array}{l}\text { Assistência religiosa; } \\
\text { Ressocialização do } \\
\text { ex-detento; Sistema } \\
\text { penitenciário } \\
\text { brasileiro. }\end{array}$ & Sudeste \\
\hline
\end{tabular}

Fonte: Construído pelas autoras (2020).

Diante da análise, foi construído um segundo quadro, permanecendo os trabalhos coerentes com a temática, sendo selecionados para uma leitura mais aprofundada, tecendo uma linha de pensamento coerente e realizando o diálogo com estudos relevantes.

Quadro 02: Referente aos títulos, perfil dos autores, objetivos, justificativas e conclusões dos trabalhos.

\begin{tabular}{|l|l|lr|l|}
\hline Título & Perfil dos autores & Objetivos & Justificativas \\
\hline $\begin{array}{l}\text { Unidade prisional como } \\
\text { espaço total: a religião na }\end{array}$ & $\begin{array}{l}\text { Mestre em Geografia, } \\
\text { especialistarilizar o }\end{array} \quad$ emétodo & A CPAI atende indivíduos \\
monográfico & e a & em privação de liberdade do \\
\hline
\end{tabular}

Educação, Psicologia e Interfaces, Volume 4, Número 3, p. 1-14, Julho/Setembro, 2020.

ISSN: 2594-5343. DOI: 10.37444/issn-2594-5343.v4i3.295 


\begin{tabular}{|c|c|c|c|}
\hline $\begin{array}{llr}\text { colônia } & & \text { penal } \\
\text { agroindustrial do } & \text { Paraná } \\
\text { (Tese) } & & \end{array}$ & $\begin{array}{l}\text { educação especial } \\
\text { inclusiva, Educação de } \\
\text { Jovens e Adultos, } \\
\text { Mídias Integrativas, na } \\
\text { Educação e Meio } \\
\text { Ambiente } \\
\text { Desenvolvimento } \\
\text { Sustentável. }\end{array}$ & $\begin{array}{l}\text { metodologia } \\
\text { dramatúrgica de Erving } \\
\text { Goffman, r sendo } \\
\text { transpostos } \\
\text { categorial geográfico } \\
\text { espaço, ao espaço do } \\
\text { cotidiano goffmaniano" } \\
\text { (MARTINS, 2017, p. } \\
\text { 08) }\end{array}$ & $\begin{array}{l}\text { sexo masculino, gozando do } \\
\text { benefício de regime } \\
\text { semiaberto e, atendendo a } \\
\text { legislação vigente, assegura o } \\
\text { cumprimento da assistência } \\
\text { religiosa. Tal característica } \\
\text { despertou o interesse pela } \\
\text { compreensão da religião para } \\
\text { o indivíduo privado de } \\
\text { liberdade. }\end{array}$ \\
\hline $\begin{array}{l}\text { Por detrás do muro cinza: } \\
\text { contribuições da } \\
\text { assistência religiosa no } \\
\text { tratamento penal (Tese) }\end{array}$ & $\begin{array}{l}\text { Iarani Augusta Galucio } \\
\text { Rocha Lauxen, é } \\
\text { doutora em Teologia, } \\
\text { pertencente a linha de } \\
\text { pesquisa: } \\
\text { Teológica no Contexto } \\
\text { Pluralista } \\
\text { Religioso }\end{array}$ & $\begin{array}{l}\text { "Investigar através do } \\
\text { estudo de caso, como } \\
\text { tem se dado a } \\
\text { assistência religiosa às } \\
\text { pessoas privadas de } \\
\text { liberdade, no } \\
\text { cumprimento do regime } \\
\text { Semiaberto no Instituto } \\
\text { Penal de São Leopoldo } \\
\text { (IPSL), Estado do Rio } \\
\text { Grande do Sul". } \\
\text { (LAUXEN 2018, p. 06) }\end{array}$ & $\begin{array}{l}\text { O trabalho foi fundamentado } \\
\text { através de dados e estudos, } \\
\text { aspectos relacionados à } \\
\text { questão penitenciária e assim } \\
\text { poder compreender a } \\
\text { emergente necessidade de } \\
\text { falar sobre o fenômeno do } \\
\text { aumento da população } \\
\text { privada de liberdade nos } \\
\text { últimos anos, e assim discutir } \\
\text { políticas concernentes ao } \\
\text { tratamento integral destas } \\
\text { pessoas durante o período de } \\
\text { reclusão, além da } \\
\text { contribuição da assistência } \\
\text { religiosa neste contexto" } \\
\text { (Lauxen } 2018 \text { pág., } 24\end{array}$ \\
\hline $\begin{array}{l}\text { Da reintegração social a } \\
\text { inclusão psicossocial: um } \\
\text { estudo com pessoas que } \\
\text { cumpriram pena de } \\
\text { privação de liberdade no } \\
\text { método } \\
\text { (Dissertação) }\end{array}$ & $\begin{array}{l}\text { Mestre em Ciências das } \\
\text { Religiões e doutorando } \\
\text { também em Ciências } \\
\text { das Religiões. }\end{array}$ & $\begin{array}{lr}\text { "Investigar } & \text { a } \\
\text { percepção que as } \\
\text { pessoas que passaram } \\
\text { por uma APAC têm } \\
\text { acerca da sua } \\
\text { experiência de } \\
\text { reintegração/inclusão } \\
\text { social". (CARDOSO, } \\
\text { 2018, p. 08) }\end{array}$ & $\begin{array}{l}\text { O autor participou da unidade } \\
\text { pesquisada no ano de } 2014 \\
\text { como estagiário. No ano de } \\
2015 \text { foi contratado como } \\
\text { psicólogo da instituição, } \\
\text { sendo fundador do setor para } \\
\text { atendimento da família. } \\
\text { Destinado ao atendimento } \\
\text { dos presos e seus familiares }\end{array}$ \\
\hline $\begin{array}{l}\text { Ressocialização mediada } \\
\text { pela assistência religiosa: } \\
\text { direito dos encarcerados no } \\
\text { sistema penitenciário } \\
\text { (Dissertação) }\end{array}$ & 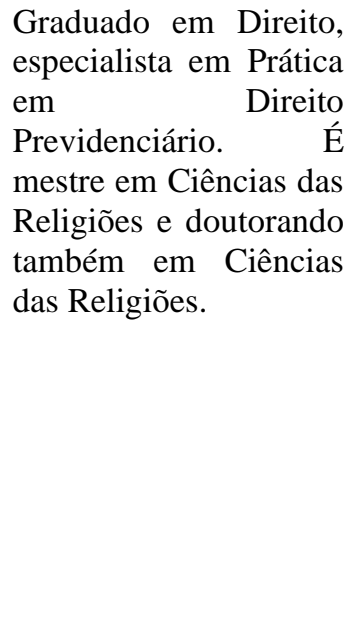 & $\begin{array}{l}\text { "Investigar } \\
\text { possibilidade }\end{array}$ & $\begin{array}{l}\text { "Configura em três níveis, } \\
\text { quais sejam: I-Acadêmico, } \\
\text { com a ampliação do acervo } \\
\text { teórico sobre o tema, o que } \\
\text { faculta novas pesquisas; II) } \\
\text { social, pelas informações } \\
\text { significativas que são } \\
\text { dispostas ao leitor que se } \\
\text { interessa por essa } \\
\text { problemática social; III) } \\
\text { pessoal, por fomentar no } \\
\text { próprio pesquisador o } \\
\text { pensamento reflexivo-crítico } \\
\text { e incitar nele a curiosidade de } \\
\text { aprofundamento no tema". } \\
\text { (COSTA, 2018, p. 08) }\end{array}$ \\
\hline
\end{tabular}

Fonte: Construído pelas autoras (2020).

Conforme descritas no quadro, chegamos às seguintes sessões de discussão: foram encontrados um total de quatro trabalhos 02 dissertações e 02 teses; as dissertações são

Educação, Psicologia e Interfaces, Volume 4, Número 3, p. 1-14, Julho/Setembro, 2020. ISSN: 2594-5343. DOI: 10.37444/issn-2594-5343.v4i3.295 
As ações das instituições religiosas dentro do sistema prisional das regiões Sul/Sudestedo brasileiro nos últimos dois anos na perspectiva de ressocialização: uma revisão bibliográfica.

pertencentes aos autores Bruno Moraes Costa e Luiz Felipe Viana Cardoso; as teses foram publicadas por Danilo Henrique Martins e Iarani Augusta Galúcio Rocha Lauxen. Os trabalhos encontrados pertencem aos programas de pós-graduação em Ciência das Religiões, Teologia, Geografia e Psicologia. Sendo um total de duas instituições públicas federais e duas instituições privadas, como demonstra o quadro abaixo.

Dentro do perfil dos pesquisadores, identificou-se apenas uma mulher que faz parte do quadro de análise, observando a predominância masculina de pesquisadores nessa temática. Quanto à metodologia que ancorou esses estudos, estas possuem aproximação no que diz respeito aos seus instrumentos de produção, a saber: entrevistas semiestruturadas, estudos de casos, análise documental e levantamento bibliográfico. Segundo Gil (1946), a pesquisa bibliográfica é indispensável nos estudos históricos, pois através dela o pesquisador poderá se permitir a cobertura de uma gama de fenômenos muitos mais amplos do que aqueles que poderiam ser pesquisados diretamente.

As produções acadêmicas trazem considerações distintas quanto às motivações pessoais de cada autor, demostradas nas justificativas dos trabalhos. As dissertações encontradas pertencem a Costa (2018) e Cardoso (2018). Em ambas cita-se o método usado pela a APAC (Associação de Proteção de Assistência aos Condenados) aos presos como medida de ressocialização. Costa (2018), em seu trabalho, traz uma sessão de revisão de literatura sobre a metodologia usada pela instituição APAC, observada em suas intervenções nos presídios do Brasil e do mundo. Os estudos de Cardoso (2018) contemplaram sua pesquisa para entendimento de toda a ideologia da APAC (seus métodos e instrumentos, utilizados no intuito de ressocializar). Para D. A. Andrade (2014, p. 27) o método APAC "parte do pressuposto de que somente recuperado o indivíduo deixa de representar um risco a comunidade".

As duas dissertações usaram o método de revisão de literatura, porém Cardoso (2018) ancorou a sua pesquisa em entrevistas semiestruturadas com os apenados da penitenciária pesquisada. As teses de doutorado encontradas para a realização deste artigo pertencem aos autores Martins (2018) e Lauxen (2018).

Martins (2018), que usou o método do espaço da dramaturgia temporal, se colocando como um participe ator para compreender o espaço geográfico e os métodos religiosos usados na penitenciária em que seus estudos ocorreram. Segundo Goffman ([1959] 2005, p. 29), “a representação é toda atividade de um indivíduo que se passa num

Educação, Psicologia e Interfaces, Volume 4, Número 3, p. 1-14, Julho/Setembro, 2020.

ISSN: 2594-5343. DOI: 10.37444/issn-2594-5343.v4i3.295 
período caracterizado por sua presença contínua diante de um grupo particular de observadores e que tem sobre esta alguma influência".

A autora Lauxen (2018), em seus estudos, traz uma análise histórica das igrejas pesquisadas por ela e sua trajetória até os dias atuais, ressaltando a importância de suas intervenções e destacando o poder que as igrejas evangélicas possuem nestes locais. Lauxen enfatiza os projetos sociais desenvolvidos pela Igreja Universal do Reino de Deus, através da UNIP (Universal nos Presídios), nas penitenciarias brasileiras. Nos dois trabalhos usou-se o levantamento bibliográfico e as entrevistas semiestruturadas.

Após análises dos trabalhos, identificamos que apenas um possui concordância com o que versa a lei de Execução Penal, n 7.210, de 11 de julho de 1984, Art. 24, inciso I e II. O trabalho de Martins (2018) enfatiza que as atuações das instituições religiosas devem respeitar as diversidades de crenças dos sujeitos, para isso devem se dispor de locais apropriados para suas práticas. Desta forma, a capela ecumênica é apresentada na tese de Martins (2018) como espaço de conveniências das diversas religiões cadastradas no local carcerário.

\subsection{Sistema prisional, ressocialização e religião: aportes teóricos}

Dentro do sistema prisional, a ressocialização tem como objetivo a humanização dos sujeitos. O detento tem a oportunidade de se formar em uma perspectiva humanista, que dará a oportunidade ao indivíduo de mudar a forma de pensar e agir na sociedade. Com isso, o sistema carcerário não se constitui em apenas privar a liberdade, mas libertar a consciência, através da educação e do trabalho.

Molina (1998, p. 381) afirma que "o decisivo, acredita-se, não é castigar implacavelmente o culpado (castigar por castigar é, em última instância, um dogmatismo ou uma crueldade), senão orientar o cumprimento e a execução do castigo de maneira tal que possa conferir-lhe alguma utilidade.” Ou seja, ação pela ação não obtém resultados, mas a ressocialização está pautada na reflexão das ações e na abertura de novas oportunidades.

Ressocializar um sujeito consiste em um efeito de longa duração. A educação, principal fonte de ressocialização, proporciona aprendizagens e criação de novos conhecimentos. Uma sociedade que apenas pune, abre a possibilidade de uma sociedade

Educação, Psicologia e Interfaces, Volume 4, Número 3, p. 1-14, Julho/Setembro, 2020.

ISSN: 2594-5343. DOI: 10.37444/issn-2594-5343.v4i3.295 
As ações das instituições religiosas dentro do sistema prisional das regiões Sul/Sudestedo brasileiro nos últimos dois anos na perspectiva de ressocialização: uma revisão bibliográfica.

cada vez mais violenta, assim como penitenciárias lotadas e grandes números de presos reincidentes.

Segundo Silva (2012) “a ressocialização é defendida como uma medida capaz de integrar o indivíduo aos demais cidadãos e em seu ciclo social básico, ou seja, sua família e amigos em uma perspectiva de inserção social". Tomando essa posição de forma efetiva, a vida pós-cárcere será diferente e terá mais facilidade de oportunidades de emprego e desenvolvimento educacional. Dessa forma, se cumpre o art. 28:

A assistência ao egresso poderá ser providenciada pelos sistemas penitenciários estaduais ou distrital, onde resida sua família, mediante convênio estabelecido entre a União e os Estados ou o Distrito Federal, a fim de facilitar o acompanhamento e a implantação de programas de apoio ao egresso (BRASIL, 2008, p. 97).

O sistema de prisão que se apresenta hoje tem como objetivo punir, prevenir e ressocializar. Segundo Melo e Leite (2014), o objetivo final da execução penal vem passando por avanços consideráveis, saindo da concepção física e moral, para uma prática ressocializadora, pois se compreende a necessidade da construção de uma sociedade mais justa e igualitária.

A religião sempre esteve presente na sociedade. Ela influencia no modo de vida das pessoas, fazendo parte dos seus costumes. Segundo Wilges (1995), a religião é um conjunto de crenças, lei e hábitos, visando um poder considerado fora dos parâmetros humanos. Ela é institucional e envolve crenças e mitos sobre a origem da vida e o sentido do mundo. As instituições religiosas estão cada vez mais presentes nos espaços públicos. Um desses espaços é no sistema prisional brasileiro, onde são desenvolvidas ações que envolvem os detentos no contato com a espiritualidade e as práticas da religião.

As ações das instituições religiosas no sistema prisional têm como medida a ressocialização; os trabalhos analisados possuem semelhanças no que diz respeito a seus métodos de intervenção. A intenção e objetivo das ações é a formação dos indivíduos, a mudança de comportamento, a valorização do outro, o cuidado e o serviço. A presença das instituições religiosas busca promover um ambiente de paz.

Educação, Psicologia e Interfaces, Volume 4, Número 3, p. 1-14, Julho/Setembro, 2020.

ISSN: 2594-5343. DOI: 10.37444/issn-2594-5343.v4i3.295 


\subsection{As ações das intuições religiosas dentro do sistema prisional brasileiro: região Sul/Sudeste}

No contexto prisional, as ações das entidades dentro do sistema prisional possuem semelhanças. São realizadas através de leituras da Palavra (versículos bíblicos), pregação por meio de aparelhos eletrônicos, que percorrem as celas e pátios, cultos designados ao testemunho de milagres com unção de óleo sagrado, equipes de obreiros destinados ao acompanhamento dos detentos, orações para afastar "demônios", sendo algumas presenciais para os presos e seus familiares

As igrejas evangélicas de origem neopentecostal dominam o cenário religioso dentro do sistema prisional. Segundo Lauxen (2018, p.83), “A Igreja Universal do Reino de Deus (IURD) é considerada um dos maiores grupos neopentecostais do Brasil". A Universal nos Presídios (UNP) realiza trabalhos de assistência espiritual e material. Seu foco não são apenas os presos, mas também oferecem assistência aos seus familiares, aos diretores dos presídios, e até mesmo aos agentes penitenciários.

No que diz respeito à diferença, foi encontrado apenas um trabalho, de uma rádio comunitária que faz parte das intervenções realizadas pela Igreja Universal do Reino de Deus, com programação proposta aos apenados. Segundo Lauxen (2018 p.86), “O Programa Momento do Presidiário é um programa existente em todo o país, bem como no Rio Grande do Sul através da 100.5 FM, há três décadas. Filiada à Rede Aleluia de Comunicação, o programa vai ao ar ao vivo todos os dias da semana, no horário das $21 \mathrm{~h}$ às $22 \mathrm{~h}$ da noite".

Nos trabalhos de Luiz Felipe Viana Cardoso (2018), intitulado "Da reintegração social a inclusão psicossocial: Um estudo com pessoas que cumpriram pena de privação de liberdade no método apac)" e Bruno Moraes Costa (2018) "Ressocialização mediada pela assistência religiosa: Direito dos encarcerados no sistema penitenciário", foi mencionado o método usado pela a APAC (Associação de Proteção de Assistência aos Condenados). Segundo Costa (2018), esta associação presta assistência aos condenados como medida para contribuir na sua ressocialização. Aos presos condenados ao regime fechado são oferecidos cursos supletivos e profissionais, além de trabalhos laborterápicos.

No regime semiaberto cuida-se da mão de obra especializada (oficinas profissionalizantes instaladas dentro dos Centros de Reintegração), no regime aberto, o 
As ações das instituições religiosas dentro do sistema prisional das regiões Sul/Sudestedo brasileiro nos últimos dois anos na perspectiva de ressocialização: uma revisão bibliográfica.

trabalho tem o enfoque na inserção social do sujeito. Este ocorre fora dos muros do Centro de Reintegração, com prestação de serviços à comunidade (Costa, 2018, p.63).

Um dos pontos importantes encontrados foi a "Capela Ecumênica", descrita por Martins (2017) em sua tese "Unidade prisional como espaço total: A religião na colônia penal agroindustrial do Paraná", apresentada como um espaço de oportunidades das diversas religiões. Na capela acontecem cultos de todas as denominações religiosas cadastradas na prisão pesquisada, sendo estes destinados aos presos e seus familiares. Seu funcionamento acontece todos os dias da semana (incluindo sábado e domingo) e todas as instituições possuem liberdade em sua maneira de atrair fieis, uma destas é a confecção de diversos banners de todas as denominações religiosas na entrada do local, com mensagens bíblicas e nomes das igrejas e horários dos cultos.

Dessa forma, a iniciativa da capela possibilita o cumprimento da Lei $\mathrm{n}^{\circ} 7.210$, de 11 de Julho de 1984, Lei de Execução Penal, no seu Art. 24: “A assistência religiosa, com liberdade de culto, será prestada aos presos e aos internados, permitindo-lhes a participação nos serviços organizados no estabelecimento penal, bem como a posse de livros de instrução religiosa". No mesmo artigo, pontua-se o inciso primeiro, que diz: "o estabelecimento haverá local apropriado para os cultos religiosos”.

Quanto as intervenções da igreja católica, através da pastoral carcerária, foram identificadas realizações de missas e equipes de acompanhamento junto aos presos. Em umas missas, foram convidados alguns detentos e seus familiares, com o critério somente para aqueles de bons comportamentos. Seus espaços de atuação são os pátios das penitenciárias, onde realizam momentos de missa.

Em análise do trabalho, a autora pontua uma das falas do representante da pastoral carcerária, em que se questionou sobre o acompanhamento de egressos do sistema penitenciário. O representante diz que "infelizmente a Igreja ainda não tem condições de atender a esta demanda, embora seja um desejo deles, pois dependem de pessoas voluntárias da comunidade para tais atividades, declarando uma falta de estrutura em relação a recursos humanos" (LAUXEN, 2018, p.104).

Sobre religiões de matriz africanas, segundo Costa (2018), estas vêm sofrendo perseguições dentro do sistema prisional. As instituições cristãs, por mais que não tenham projeto específico, conseguem abertura com maior facilidade. Na entrevista realizada por Costa (2018), a Mãe de Santo da Casa do Perdão, Flávia Pinto, publicou um artigo 
dizendo: "pessoas pouco esclarecidas, de mentes fechadas, fanáticas e bitoladas, que nos discriminaram, nos desrespeitaram. Só entramos porque o assunto foi para o jornal e o "DESIPE142", no dia seguinte, nos aprovou em menos de 24 horas". E conclui: "Mas fomos fortes e não desistimos" (COSTA, 2018, p.46).

\section{CONSIDERAÇÕES FINAIS}

Este estudo teve como objetivo analisar/pontuar quais as propostas de ressocialização que as instituições religiosas do Sul/sudeste fazem dentro do sistema prisional brasileiro nos últimos dois anos. Os resultados nos apontaram que as atividades religiosas no sistema prisional possuem semelhanças em seus métodos para ressocializar. Suas ações colaboram com assistência espiritual, médica, jurídica e psicológica aos apenados e seus familiares. Corroboram ainda com diversos cursos profissionalizantes que são ofertados de acordo com o regime em que o preso se encontra (aberto, semiaberto ou fechado).

Após a análise dos trabalhos, os resultados evidenciaram que as igrejas evangélicas dominam o cenário religioso no sistema prisional. A universal do Reino de Deus (IURD) possui uma grande equipe nas realizações desses trabalhos. Seu campo de atuação abrange diversos estados brasileiros, esta faz parte da corrente espiritual neopentecostal. A Igreja Católica, através da pastoral carcerária, possui o método de evangelizar através da palavra bíblica, com missas destinadas aos detentos e seus familiares. Já os adeptos das religiões de matrizes africanas relatam sofrer atos preconceituosos dentro do sistema prisional, no que diz respeito a sua ideologia religiosa.

A partir dos resultados deste estudo, verificamos que a temática das propostas de ressocialização, através das instituições religiosas, abriu margem para pesquisas e estudos posteriores que comtemplassem o preconceito religioso das religiões de matrizes africanas, pois através das análises dos trabalhos compreendemos que os detentos adeptos desta religião omitiam suas crenças devido aos atos discriminatórios por parte dos colegas de cela, funcionários dos presídios e dos próprios membros das instituições religiosas que predominavam nos cárceres.

Os resultados também nos levaram a refletir sobre a falta de pesquisas dos trabalhos religiosos nas penitenciárias da área do Nordeste, uma vez que essa região possui um grande índice de encarcerados do Brasil. Por fim, este estudo pretende 
As ações das instituições religiosas dentro do sistema prisional das regiões Sul/Sudestedo brasileiro nos últimos dois anos na perspectiva de ressocialização: uma revisão bibliográfica.

colaborar de forma significativa para a realização de futuros trabalhos acadêmicos na região nordeste/Bahia, já que os resultados da pesquisa apontaram a ausência de trabalhos que contemplem a temática religiosa no sistema prisional deste estado/região.

Por fim, vale salientar que, diante dos dados encontrados neste estudo, levando em consideração que as produções acadêmicas com a temática aqui proposta necessitam de visibilidade, não somente no cenário acadêmico, mas no âmbito social para futuras discursões e debates, é que este artigo será publicado posteriormente em uma revista intitulada de "Revista Educação, Psicologia e Interfaces".

\section{REFERÊNCIAS}

Brasília-DF: Ministério da Justiça SLAKMON, Catherine; MACHADO, Maíra Rocha; BOTTINI, Pierpaolo Cruz (Orgs.). Novas Direções na Governança da Justiça e da Segurança. 2006.

BRASIL. Constituição (1988). Constituição da República Federativa do Brasil. Brasília, DF, Senado, $1998 . \quad$ Disponível em: http://www.planalto.gov.br/ccivil_03/constituicao/ConstituicaoCompilado.htm. Acesso em 15 de jan. de 2020.

COSTA, Bruno Moraes. Ressocialização mediada pela assistência religiosa / Direito dos encarcerados no sistema penitenciário. 2018.x, f. 109. Dissertação (mestrado) UNIDA / Faculdade Unida de Vitória, 2018.

FREIRE, P. Pedagogia da autonomia: saberes necessários a prática educativa. São Paulo: Paz e Terra, 2011.

KANT, TEIXEIRA, A. Educação não é privilégio: revista ampliada. São Paulo: Editora Nacional, 1967.

LAUXEN, Iarani Augusta Galucio Rocha. Por detrás do muro cinza: Contribuições da assistência religiosa no tratamento penal, 2018, 256p. Tese (Doutorado em Teologia) Faculdades EST. São Leopoldo,2018.

MINAS, PUC. Programa de pós-graduação em Ciências da religião. https://www.puccampinas.edu.br/pos-graduacao/programa-de-pos-graduacao-em-ciencias-da-religiaomestrado-2/. Acesso em 12 fev de 2020.

\section{Credenciais das autoras}

Educação, Psicologia e Interfaces, Volume 4, Número 3, p. 1-14, Julho/Setembro, 2020.

ISSN: 2594-5343. DOI: 10.37444/issn-2594-5343.v4i3.295 
PEREIRA, Ediene Valéria Dourado Guimarães. Graduada em Pedagogia pela Universidade do Estado da Bahia, UNEB - campus XII. E-mail: edienedouradogbi@gmail.com.

SILVA, Sandra Célia Coelho Gomes. Professora na Universidade do Estado da Bahia UNEB - Campus XII, graduada em Ciências Sociais (UNIVALE), especialista em Sociologia (UFMG), Doutora e mestra em Ciências da Religião (PUC/GO), Pós-doc em Educação e Contemporaneidade (UNEB). E-mail: scsilva@uneb.br.

Endereço para correspondência: Ediene Valéria Dourado Guimarães. Rua Epitácio Pessoa, $n^{\circ} 162$, bairro Novo Horizonte.

Como citar este artigo (Formato ABNT): PEREIRA, Ediene Valéria Dourado Guimarães. SILVA, Sandra Célia Coelho Gomes. As ações das instituições religiosas dentro do sistema prisional das regiões Sul/Sudestedo brasileiro nos últimos dois anos na perspectiva de ressocialização: uma revisão bibliográfica. Educação, Psicologia e Interfaces, v. 4, n.2, p. 1-14, 2020.

Recebido: 07/04/2020.

Aceito: 20/05/2020. 